that these factors-pelvic infection and use of intrauterine contraceptive devices-have a role, but this remains to be proved; demographic factors probably account for the consecutive rise in incidence in the five year age groups. If factors related to age have a decisive effect on the rise in ectopic pregnancy, the numerical increase in cases will level off within a few years in Finland.

I thank Dr Robert Paul and Dr Tuula Salmi for their valuable comments on the manuscript; Ms Anja Rasimus for help with the statistics; and Ms Liisa Rehnström for secretarial help.

Weckstein LN. Current perspective on ectopic pregnancy. Obstet Gynecol Surv 1985;40:259-72. DeCherney AH, Jones EE. Ectopic pregnancy. Clin Obstet Gynecol 1985;28:365-74.

3 Chavkin W. The rise in ectopic pregnancy-exploration of possible reasons. Int $\mathcal{f}$ Gynaecol Obstet Chavkin W. The rise $1982 ; 20: 341-50$.
1

4 Barnes $\mathrm{AB}$, Wennberg $\mathrm{CN}$, Barnes $\mathrm{BA}$. Ectopic pregnancy: incidence and review of determinant factors. Obstet Gynecol Surv 1983;38:345-56.

5 Weström L, Bengtsson LPH, Mårdh P-A. Incidence, trends, and risks of ectopic pregnancy in a population of women. $\mathrm{Br} M e d \mathcal{F} 1981 ; 282: 15-8$.

(Accepted 31 December 1986)

Department of Obstetrics and Gynaecology, University Central Hospital of Turku, SF-20520 Turku, Finland

JUHA I MÄKINEN, MD, specialist gynaecologist and obstetrician

\section{Treatment of palindromic rheumatism with chloroquine}

Palindromic rheumatism consists of recurrent self limiting attacks of monoarthritis or oligoarthritis, often precipitated by exercise, lasting from a few hours to a few days. There is complete remission between episodes, but the disease may be disabling and may progress to classical rheumatoid arthritis. We report three cases that responded dramatically to treatment with chloroquine.

\section{Case reports}

Case 1-A 33 year old man presented with a five year history of intermittent pain and swelling of shoulders, elbows, wrists, metacarpophalangeal joints, and knees typical of palindromic rheumatism. A wide variety of anti-inflammatory drugs had been ineffective. Erythrocyte sedimentation rate was $6 \mathrm{~mm}$ in the first hour, serum urate concentration normal, and antinuclear factor and the results of a latex slide test negative. $x$ Ray films were normal. Despite treatment with naproxen and penicillamine he remained severely disabled by up to five attacks a week. Encouraged by a report on the efficacy of chloroquine in palindromic rheumatism, ${ }^{1}$ we started treatment with $250 \mathrm{mg}$ daily. The morning after his first dose he felt "as if a switch had been turned off." He had no further attacks and regained full activity, which was maintained with treatment on alternate days. This was stopped after two years because of electroretinal abnormalities. He then had two mild attacks in three months but was subsequently free of symptoms for seven years without any treatment.

Case 2-A 19 year old woman presented with an eight year history of recurrent episodes of pain and swelling in fingers, knees, and ankles. Attacks occurred up to three times a week, lasted for 24 hours, and were exacerbated by exercise and cold weather. Her mother had rheumatoid arthritis and a paternal uncle ankylosing spondylitis. Several non-steroidal anti-inflammatory drugs given over the next year were ineffective, but $250 \mathrm{mg}$ chloroquine daily stopped further attacks. Chloroquine was then given on alternate days and later stopped; her attacks recurred within a few days. The drug was reintroduced, and she remained symptom free for three years.

Case 3-A 53 year old woman was admitted with excrucrating left hip pain that had begun a few hours before. During the previous six weeks she had suffered pain in both shoulders, the left wrist, and the right knee. She had previously undergone parathyroidectomy for hyperparathyroidism. Her mother and paternal grandmother had rheumatoid arthritis. The erythrocyte sedimentation rate was $4 \mathrm{~mm}$ in the first hour; a sheep cell agglutination test gave a titre of $1 / 16$; and a test for antinuclear factor gave a negative result. $x$ Ray films of her joints were normal. Despite indomethacin treatment she continued to have flitting joint pains and swelling and was readmitted with severe right hip pain: a sheep cell agglutination test gave a titre of $1 / 128$. Her joint symptoms resolved with treatment with chloroquine, and she remained well for 18 months.

\section{Comment}

Palindromic rheumatism is a clinical diagnosis and does not represent a single entity. In some patients it is an unusual presentation of what will ultimately become rheumatoid arthritis: one of our patients (case 3 ) was followed up for two years after her joint symptoms first developed, had a raised titre once on sheep cell agglutination testing, and may well have been such a patient. Her response to chloroquine was nevertheless much more rapid than that expected in more typical rheumatoid arthritis. Our other patients had severe joint symptoms for years without joint damage or progression to rheumatoid arthritis. Both received many antiarthritic drugs with little effect but responded to chloroquine promptly and completely.

As far as we know the efficacy of chloroquine in palindromic rheumatism has been reported only once previously. We believe that the possibility of such a remarkable response to chloroquine should render it a first line drug in palindromic rheumatism. By comparison with gold and penicillamine, which have also been recommended, ${ }^{23}$ chloroquine is safe provided that the eyes are monitored routinely. ${ }^{4}$

\section{We thank Dr J P Delamere for helpful discussion.}

1 Golding DN. D-Penicillamine in palindromic rheumatism. Br Med $\mathcal{f}$ 1976;ii:1382-3.

2 Mattingly S. Palindromic rheumatism. Ann Rheum Dis 1966;25:307-17.

3 Huskisson EC. Treatment of palindromic rheumatism with D-penicillamine. BrMed f 1976;ii:979.

4 Marks JS, Power BJ. Is chloroquine obsolete in treatment of rheumatic disease? Lancet 1979; 371-3.

(Accepted 12 December 1986)

Wordsley Hospital, Stourbridge, West Midlands DY8 5QX

M R RICHARDSON, BSC, MRCP, senior house officer

A M ZALIN, MD, FRCP, consultant physician

Correspondence to: Dr Zalin.

\section{Indigenous strongyloidiasis in Nottingham}

Strongyloidiasis, a nematode infection of wet tropical regions, may be an unexpected hazard of walking barefoot in Nottingham parks. We believe that this is the first report of an autochthonous case in Britain.

\section{Case report}

A 17 year old white schoolgirl presented with a six month history of diarrhoea, anorexia, and $4 \mathrm{~kg}$ weight loss. She had had several sloppy motions each day but no blood or mucus in the stools. She had undergone extensive investigation for evidence of chronic inflammatory bowel disease but had yielded negative results on upper gastrointestinal endoscopy and biopsy of the small intestine; sigmoidoscopy and rectal biopsy; and radiology of the stomach and the small and large intestines. The only apparent abnormality was a persistent eosinophilia of $2.3 \times 10^{9} / 1$ (33\% of total white blood cells), $3.67 \times 10^{9} / 1(28 \%)$, and $5.94 \times 10^{9} / 1$ (44\%) at intervals throughout her illness. Examination of her stools on several occasions showed large numbers of rhabditiform larvae of Strongyloides stercoralis. She was treated with thiabendazole $1.5 \mathrm{~g}$ twice daily for three days, which resulted in improvement of her symptoms, elimination of the larvae from the faeces, and reduction of the eosinophilia. Stools from the family and pet dog all yielded negative results.

She was questioned further about a possible origin for her infection. She had never travelled abroad, except for a day trip to Boulogne many years previously, and none of her family, friends, or visitors had visited the tropics. The family had lived in the same council house in Nottingham for 17 years. The only important point was that she always walked around at home and in local parks barefoot.

\section{Comment}

$S$ stercoralis is a common intestinal parasite in the wet tropics, the southern states of the United States, and warmer parts of Europe. Though chronic infestation with the parasite has been shown in ex-prisoners of war more than 30 years after their return from South East Asia, ${ }^{12}$ there have been no reports of patients contracting the disease while living in Britain.

The common mode of infection is from a larval reservoir in wet warm soil, where the rhabditiform larvae develop into the infective filariform stage. These filariform larvae penetrate the skin of the feet, entering blood vessels to reach the lungs. They then migrate through the trachea and pharynx to the small intestine, where they mature and multiply. Having buried themselves in the wall of the small intestine, fertilised females produce eggs that develop into the rhabditiform larvae. Rhabditiform larvae may become filariform before being shed in the stool, allowing autoinfection to occur through the gut mucosa or perianal skin without an intermediate soil phase. Under suitable environmental conditions a free living cycle may be established in the soil. 